\title{
An International Comparison of Blended Learning
}

\author{
Fatima Al-Qaoud ${ }^{1,2}$, Andrew Carruthers ${ }^{2}$, Mumtaz Kamala ${ }^{2}$, Sami Habib ${ }^{1}$ and Raed Abd- \\ Alhameed $^{2}$ \\ $\left\{\underline{\text { fnhalqao@bradford.ac.uk }}{ }^{1,2}\right.$, A.Carruthers@bradford.ac.uk ${ }^{2}$, m.a.kamala@bradford.ac.uk $\left.{ }^{2}\right\}$ \\ ${ }^{1}$ Kuwait University, Block 4, Al-khaldiya, Kuwait. \\ ${ }^{2}$ Faculty of engineering and informatics, University of Braford, Bradford, BD7 1DP, UK.
}

\begin{abstract}
This paper presents an investigation into the implementation of blended learning (BL) in several countries where it has been used in schools to enhance the learning outcomes of students through the utilisation of technology in education. BL means integrating traditional tools of teaching with technical tools such as online learning through websites, CDs, and videos. To implement a sustainable BL environment, an IT infrastructure must be built including PCs and network access. This enables students to connect to the internet during the class to access educational web-based content as well as to share discussions about subjects with their peers in and out of the class. Developed countries in different regions such as USA, Europe, and the Far East have applied BL in their educational systems.
\end{abstract}

Keywords: Blended Learning BL, IT infrastructure, online learning, E-learning, technology, education, and pedagogy.

\section{Introduction}

The implementation of Blended Learning (BL) is rapidly expanding internationally and now includes the USA, UK, Australia, Belgium, Turkey, Indonesia, China and several countries in Africa. The emerging theme from discussions in all of these regions is the need to develop students' academic attainment by implementing the latest educational technology tools among students in high schools. BL has many definitions in the literature; Powell [1] defines BL as 'hybrid learning, [which] combines the best features of traditional schooling with the advantages of online learning to deliver personalized, differentiated instruction across a group of learners'. BL is one of the most effective approaches that have been used recently in schools to enhance the learning of students by accessing different media. The unique feature of BL is that it integrates the traditional way of "whiteboard" teaching in the class with online tools such as videos, CDs, and websites. BL thus enables students to better appreciate lessons through watching videos online, to engage with lively discussions, prepare for the subject before attending the class, and to interact with peers to discuss topics online outside of formal teaching hours.

Educational psychologists and behaviourists have presented many theories, which have influenced the process of acquiring knowledge that can be understood. Through learning theory, teachers can easily measure students' acquisition of knowledge and to understand the emotional concomitants of students' learning and acquiring relevant information in the classroom. Additionally, learning theory considers the cognitive and environmental factors that directly influence students' comprehension and competencies.

A broad understanding of pedagogy was provided by Alexander [2] who defined it as "the observable act of teaching together with its attendant discourse of educational theories, values, 
evidence, and justifications. It is what one needs to know, and the skills one needs to command, in order to make and justify the many different kinds of decisions of which teaching is constituted" [2].

This work presents a framework for enhancing education in Kuwait through utilising the most effective tools in a BL process to achieve successful outcomes for students and thus enable them to be more creative and innovative as future leaders.

\section{The Theoretical Framework of BL in USA}

Blended learning is an educational strategy, which merges the traditional classroom with online activities and finds its best application in the flipped classroom that enables students to have direct access to the contents of the lesson before going to school. In this context, the teacher becomes a supporter and facilitator and assists students to transfer from knowledge to the acquisition of skills and competencies [3]. Exploring some approaches in the field of blended learning will create a new student-centred learning environment to enable access to courses available in different media.

Clayton Christensen conducted research on blended learning schools and programmes, and found that the majority of blended programmes may be categorised as one of the following four models: Rotation, Flex, A La Carte, and/or Enriched Virtual. Powell, A., et al. (2015) [1] defined the Rotation Model as "Any course or subject in which students rotate-either on a fixed schedule or at the teacher's discretion-among learning modalities, at least one of which is online learning". The Flex Model requires that the student must have an online course or subject as an essential component of her/his learning, even with offline activities at times. The teacher of record is on-site, and students learn mostly on a brick-and-mortar campus, except for any homework. On the other hand, when the student takes the A La Carte Model, this means that the course is entirely online to accompany other experiences that the student has enrolled on at a brick-and-mortar school or learning centre, and the teacher is the online teacher. When a student takes a course or subject that requires face-to-face learning sessions with his own teacher, then it can be said that that student is experiencing the Enriched Virtual Model. However, the student is free to complete their remaining coursework remotely from the face-to-face teacher. Case studies have been conducted in seven districts in USA to apply different BL models in mathematics and English/language arts (ELA) subjects. The creation of school culture and climate dedicated to continuous improvement enhances the educational process [1].

To measure elementary students' engagement in a blended educational technology course requires collecting both self-reported and observational data. Such data has a significant potential to increase the understanding of the relationship between vital characteristics and student engagement [4].

Briggs \& Crompton [5] suggested that Massive Open Online Courses (MOOCS) should be applied for students in K-12. These students had often suffered from inadequate training, time management and effective utilisation of available resources to implement learner-centred digital instruction. The researchers were faced with certain challenges and, for that reason, they proposed the integration of MOOCS with the traditional instructions to enhance the educational framework. MOOCS is an online platform that enables educators to access free pedagogic courses. With the advent of technology solutions in education, having an online environment for K-12 students with the implementation of MOOCS in schools became mandatory after the successful experience found with higher education students [5]. 
Blended learning provides anytime and anywhere access to massive volumes of learning materials and course content over the internet. This enables teacher-student interaction and rapid feedback on the course development of students through in-class meetings and online tools. It also facilitates the implementation of curriculum with standards, eliminating any confusion that the students might have faced during the class [6].

With the utilisation of screencasts, students will ideally have more time for discussion in class and more chance to review concepts and theoretical perspectives outside of class. It is difficult to measure the impact of blended learning on students' academic performance and learning outcomes in this exploratory study, despite the indication of the high usage of screencasts by students. In conclusion, this study presented an optimistic initial appraisal of the prospects for blended learning [7].

Moskal (2013) debated the issue of whether BL was a dangerous idea or a supportive one for higher education learning in the University of Central Florida UCF. Over sixteen years of illustrations with effective advocating and planning, the evolution of BL has raised the issue that institutions should reallocate, transform and control its resources [8]. The statistics relevant to students' levels of satisfaction with their learning experience based on ratings showed that the highest percentage (52\%) of "excellent" responses were given to BL as an 'Excellent" response as shown in the pie chart in Figure 1. [8] below.

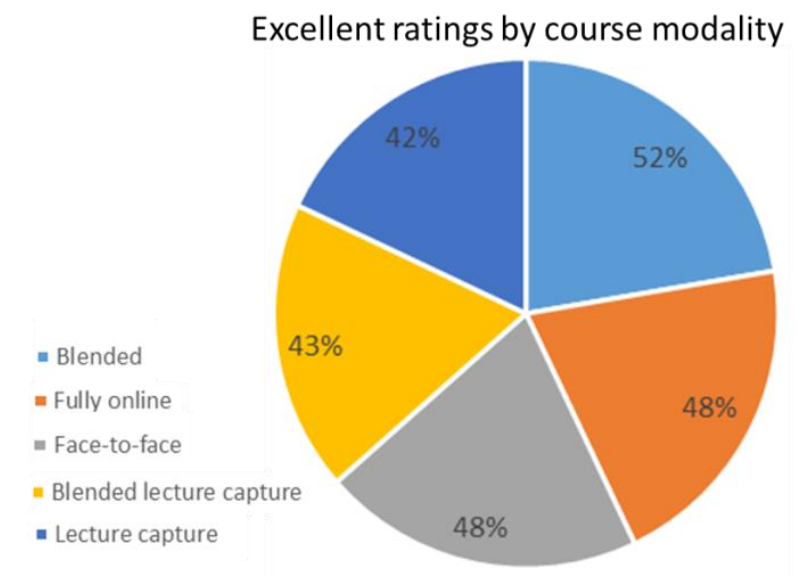

Fig. 1. Excellent ratings by course modality

\section{The Theoretical Framework of BL in Europe and Other Countries}

Several reviews of BL from Europe, Australia and New Zealand are provided below. These studies highlight the different experiences and methodologies used to implement BL. However, while good practices are identified, there is still a 'gap in the knowledge' and more studies are needed to enhance our understanding. 


\subsection{United Kingdom}

Exploring schemes of instructors when implementing blended learning, educational objectives and instructional design are useful when focusing on instructors' skills education, and conceptions in selecting technological tools. Most of the academics supported blended learning because it enhanced teaching and learning objectives. It was found that implementing BL resulted in a more effective student-learning process. Regarding instructional design, the study found that different blended learning instruments had been used, including electronic tools such as Kindles, electronic voting, online discussion forums, videos, podcasts, and social networking tools. Academics did not plan to arrange criteria during utilisation of instruments and methods [9].

As technology increasingly modifies aspects of path, speed, time and place in our own lives, it is also affecting the acceleration of teaching and learning. Furthermore, teachers identify opportunities to embed learning experiences for their students that blend face-to-face and online environments, which require enrolling teachers into graduate programs that emphasise online learning [10].

A holistic approach was required to successfully implement institutional conversion towards enhanced blended learning. Therefore, implementing such a framework needed more discussions with the institutional team to identify key points that the university could use to enhance the blended learning phase [11].

Three critical issues for implementing BL to improve academics' competences and confidence using technologies create consistent definitions and optimal frameworks to assess BL practice. The framework could assist academic staff to identify their current standard of BL practice, but some changes are required to improve to meet higher standards. Institutions could adopt the framework of BL to assign their own BL definitions and policies. The proposed framework included three levels of descriptive standards with the fourth level for faculties to address their own disciplinary and contextual needs. Three challenges impeded the development of BL in higher education: The first was the lack of digital fluency and competencies among academics in using online technologies, despite the availability of a digital environment. The second was the standardisation of understanding BL in the educational field which was absent. Thirdly was the inadequacy of available instruments to guide and evaluate BL course designs. Therefore, they proposed a standards-based BL framework based on one definition, providing a consistent understanding of BL practice [12].

\subsection{Italy}

The best organisation for BL is the flipped classroom where the students view online articles and watch videos off-class and at home where they prepare lessons for the next day. BL positively presented new communication networks among students, allowing them to interact with each other to share ideas, to analyse a work of art, to organise art galleries and to collaborate to perform for better achievements [3].

\subsection{Australia}

To predict the value of strategies for academic improvements in Melbourne, Australia, an exploration of differences between entirely online students and blended learning students is needed when they utilise various self-regulated learning (SRL) strategies. The concept of self- 
regulation is that the learner must be motivated, persistent and enabled to manage time effectively by setting plans, goals and being involved in strategies to accomplish them. Both grade results of online students and blended students were almost equivalent, in spite of some differences based on the utilisation of SRL strategies. Using strategies such as time management, elaboration with the elimination of rehearsal strategies is highly significant for both online and blended learning students [13].

High-regulators preferred some assistance from teachers and peers, whereas self-reliant regulators preferred to have less interaction. Thus, online students were more likely to adopt an SRL profile than blended learning students were [14].

According to Entwistle, McCune, \& Hounsell (2002)[15], factors influencing the quality of learning at Nottingham Trent University (NTU) depended on course content presentation and both the style of teaching-learning environment provided beside the students' perceptions of this environment as shown in Figure 2. [16].

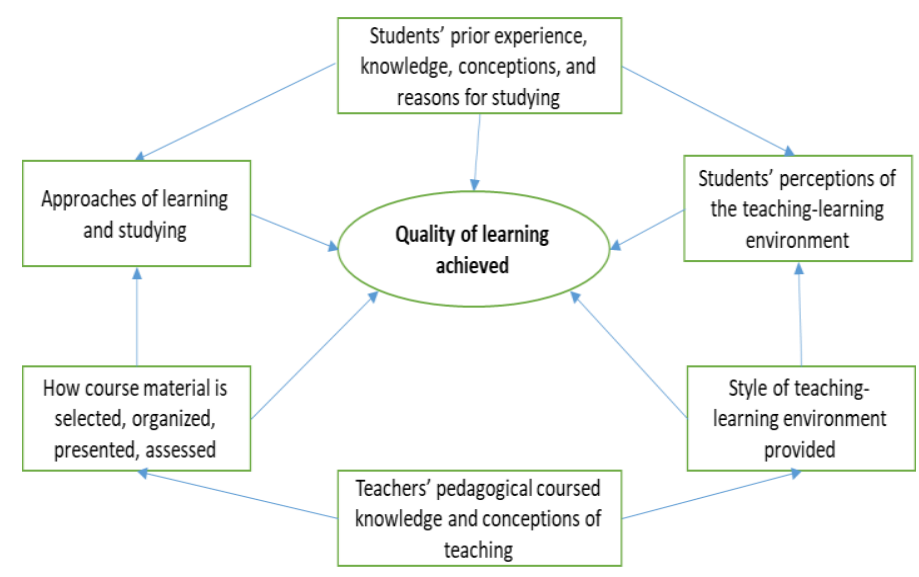

Fig. 2. Concepts related to the quality of learning at university.

\subsection{New Zeland}

It is necessary to know how to apply the BL approach for learning experiences outside school (LEOS) through using Digitally Integrated Fieldtrip Inventory model (DIFI) and improving cognitive learning outcomes. DIFI used three pedagogical approaches; cognitive, procedural, and social. Those components could present opportunities for increasing cognitive learning outcomes through LEOS. It is suitable for highly motivated students, helping them to innovate new ways of thinking, interpreting, and analysing information. Teachers must prepare themselves for such experience for better learning outcomes and plan well to prepare for LEOS because they did not plan well for pre-and post-visit activities [17]. 


\section{The BL Implementation Methodology Comparison}

In the USA, different methodologies were adopted than those in Europe and other countries mentioned above. Web-based surveys have been used, in the USA, models, techniques and programmes. On the other hand, Europe and other countries have focused on interviews and surveys rather than technical models or frameworks. Accordingly, the different results which have been obtained from those studies are shown in Table $\mathbf{1 .}$

Table 1. Comparison of methodologies used to implement BL between USA and European countries.

\begin{tabular}{|l|l|l|}
\hline Country & Methodology used & Citation \\
\hline \multirow{5}{*}{ USA } & Cooperative Learning technique & Capone[3] \\
\cline { 2 - 3 } & $\begin{array}{l}\text { Case studies include practising of } \\
\text { one or more model of BL }\end{array}$ & Powell [1] \\
\cline { 2 - 3 } & A survey, and user activity & Henrie[4] \\
\cline { 2 - 3 } & $\begin{array}{l}\text { Massive Open Online Courses } \\
\text { (MOOCS) }\end{array}$ & $\begin{array}{l}\text { Briggs \& } \\
\text { Crompton [5] }\end{array}$ \\
\cline { 2 - 3 } & $\begin{array}{l}\text { Cisco Certified Network Associate } \\
\text { (CCNA) program }\end{array}$ & Çakır [6] \\
\cline { 2 - 3 } & web-based surveys & Auster[7] \\
\hline \multirow{5}{*}{ UK } & semi-structured interview & Benson[9] \\
\cline { 2 - 3 } & $\begin{array}{l}\text { Instructional Technologies \& } \\
\text { Digital Media Literacy Programme, } \\
\text { a workshop period called Digital } \\
\text { Texts and Tools }\end{array}$ & O'Byrne[10] \\
\cline { 2 - 3 } & semi-structured interviews & Adekola[11] \\
\cline { 2 - 3 } & $\begin{array}{l}\text { A combination of logical, rational } \\
\text { and theoretical approaches }\end{array}$ & Mirriahi[12] \\
\hline Italy & $\begin{array}{l}\text { Cooperative Learning application } \\
\text { (CL) }\end{array}$ & Capone[3] \\
\hline Australia & Survey interviews and & Broadbent[13] \\
\cline { 2 - 3 } & $\begin{array}{l}\text { A demographic survey } \\
\text { Coll [17] }\end{array}$ \\
\hline $\begin{array}{l}\text { New } \\
\text { Zealand }\end{array}$ & $\begin{array}{l}\text { Qualitative case study included } \\
\text { multiple } \\
\text { observations }\end{array}$ & \\
\hline
\end{tabular}

\section{Results and Discussions}

The results showed that all research studies discussed the implementation of BL with different methodologies, but none of them found an agreed standard for BL. For instance in USA, most of the methodologies used were based on technical approaches or programmes. Capone[3] used the Cooperative Learning technique, which enables students to work together in small groups to achieve common goals and improve their learning by helping each other. On the other hand, Powell [1] used case studies that included following one or more models of BL in math and English/language arts (ELA) subjects. According to Clayton Christensen's research, the majority of blended programs fall into one of four models: Rotation, Flex, A La Carte or 
Enriched Virtual [1]. The findings of this study revealed that the blended programme at the elementary school effectively improved math scores on state assessments. However, customised instruction requires more than placing a student in front of a computer and connecting them online and a self-paced digital curriculum may be a useful component of a larger instructional model, but it does not create blended or proficiency-based pathways.

Another study in the USA used two kinds of methodology, a survey of students' points view of the learning activity, and user activity on the Learning Management System (LMS) recorded as log data [4]. Unfortunately, this research was difficult to evaluate; besides, some limitations were found to be related to the comparison between face-to-face, online schemes, and blended learning in terms of student' success [4]. Additionally, two web-based surveys were distributed to students, one at the beginning of the semester and the other one at the end of the semester, to measure the improvement based on the utilisation of screencasts [7]. However, the study revealed that there was difficulty in measuring the impact of blended learning on students' academic performance and learning outcomes in this exploratory study, despite the indication of high usage of screencasts by students [7].

In contrast, in Europe, the most dominant methodology for assessing the effectiveness of BL were semi-structured interview and surveys [11], while O'Byrne[10] used Instructional Technologies \& Digital Media Literacy Program, designed as a hybrid, or blended, learning programme besides, a workshop period called Digital Texts and Tools to explore digital instruments and ultimately allowing students to create online tutorials using screen-casting.

Semi-structured interviews have been conducted at the University of Glasgow to assess their levels of involvement in and experience of blended learning, and to find ideas that might contribute to building a holistic framework through presenting reasons for change agents, what institutional considerations needed to be made and how organisations would arrange to implement the framework [11]. The University of Glasgow required a holistic approach to implement a successful institutional transition towards enhanced blended learning. Thus, implementation of this framework needed effective discussions with the institutional teams to identify key points that the university could use to enhance the blended learning phase[11].

\section{Conclusions}

Technology is a vital component of the contemporary educational system. BL is one of the most usable approaches in developed countries to enhance the level of students' outcomes. It is important to find the ultimate standard for BL to be adopted to be used among educational systems. The results show that there is currently no standardisation for BL. Interviews and surveys have been conducted with different samples from different countries, but some barriers and limitations prohibited accurate results. Besides, several models have been applied in USA without addressing the most effective model to be taken as a standard model. Therefore, more studies with accurate measurements are needed to be developed. Decision-makers, experts, and technicians should be involved when designing a BL model. A clear framework is needed to design, implement, test, and then release the best possible BL model with the capability to adapt to future needs. 


\section{References}

[1] Powell, A., et al.: Blending Learning: The Evolution of Online and Face-to-Face Education from 2008-2015. Promising Practices in Blended and Online Learning Series. International Association for K-12 Online Llearning, (2015)

[2] Alexander, R.: Education For All, The Quality Imperative and the Problem of Pedagogy. CREATE Pathways to Access. Research Monograph No. 20 (2008)

[3] Capone, R., De CaterinaP., and Mazza G.: Blended Learning, Flipped Classroom and Virtual Environment: Challenges and Opportunities for the 21st Century Students. Procedings of EDULEARN 2017, Barcellona (2017)

[4] Henrie, C.R., BodilyR., and ManwaringK.C.: Exploring Intensive Longitudinal Measures of Student Engagement in Blended Learning. Vol. 16, pp. 3. International Review of Research in Open and Distance Learning (2015)

[5] Briggs, S. and Crompton, H.: Taking advantage of MOOCs in K-12 education: A blended approach, in Online Course Management: Concepts, Methodologies, Tools, and Applications. pp. 1189-1201 (2018)

[6] Çakır, H. and Bichelmeyer,B.A.: Effects of teacher professional characteristics on student achievement: an investigation in blended learning environment with standards-based curriculum. Vol. 24, pp. 20-32.Interactive Learning Environments, (2016)

[7] Auster, C.J.: Blended Learning as a Potentially Winning Combination of Face-to-face and Online Learning: An Exploratory Study. Vol. 44, pp. 39-48. Teaching Sociology, (2016)

[8] Moskal, P., Dziuban,C. and Hartman,J.: Blended learning: A dangerous idea? Vol. 18, pp. 1523. The Internet and Higher Education, (2013)

[9] Benson, V. and Kolsaker,A.: Instructor Approaches to Blended Learning: A Tale of Two Business Schools. Vol. 13, pp. 316-325.International Journal of Management Education, (2015)

[10] O'Byrne, W.I. and Pytash,K.E.: Hybrid and blended learning. Vol. 59, pp. 137-140. Journal of Adolescent \& Adult Literacy, (2015)

[11] Adekola, J., Dale,V.H.M. and Gardiner,K.: Development of an institutional framework to guide transitions into enhanced blended learning in higher education. Vol. 25, pp. 1-16. Research in Learning Technology, (2017)

[12] Mirriahi, N., Alonzo,D. and Fox, B.: A blended learning framework for curriculum design and professional development. Vol. 23, pp. 1-14. Research in Learning Technology, (2015)

[13] Broadbent, J.: Comparing online and blended learner's self-regulated learning strategies and academic performance. Vol. 33, pp. 24-32. The Internet and Higher Education, (2017)

[14] Broadbent, J. and Fuller-Tyszkiewicz,M.: Profiles in self-regulated learning and their correlates for online and blended learning students. Educational Technology Research and Development, pp. 1-21 (2018)

[15] Entwistle, N., McCune,V. and Hounsell, J.: Approaches to studying and perceptions of university teaching-learning environments: Concepts, measures and preliminary findings. Enhancing Tteaching and Llearning Environments in Undergraduate Courses Occasional Report. pp. 1-19 ( 2002)

[16] Poon, J.: Blended learning: An institutional approach for enhancing students' learning experiences. Vol. 9, pp. 271-288. Journal of Online Learning and Teaching, (2013) 
[17] Coll, S.D. and Coll, R.K.: Using blended learning and out-of-school visits: pedagogies for effective science teaching in the twenty-first century. Vol. 36, pp. 185-204. Research in Science and Technological Education, (2018) 